\title{
Size selection by the crab Liocarcinus puber feeding on mussels Mytilus edulis and on shore crabs Carcinus maenas: the importance of mechanical factors
}

\author{
T. ap Rheinallt \\ School of Animal Biology, University College of North Wales, Bangor, Gwynedd LL57 2UW, United Kingdom
}

\begin{abstract}
Velvet swimming crabs Liocarcinus puber (L.) were observed while they fed on mixtures of different size classes of mussels Mytilus edulis L. or of juvenile shore crabs Carcinus maenas (L.) in the laboratory. Intermediate-sized mussels predominated in the diets. Numbers of contacts with different sized mussels corresponded to the ratios presented, but contacts with smaller individuals frequently evoked no grasping attempts. Due to limited chelal dexterity, small mussels were difficult to grasp and easily dropped. Some large resistant mussels were rejected after unsuccessful breaking attempts. The factors determining size selection also determined profitability, since gleaning of flesh from small prey was inefficient and involvement time with large prey very long. Thus for mussels prey profitability and diet composition were similar. Large shore crabs were eaten most frequently. Being more active, they were contacted more frequently than expected from the ratios presented. Small shore crabs were difficult to grasp and easily dropped. Within the size range used, there was no mechanical upper size limit to predation. For this prey, predation slowed down as more food was ingested. apparently limited by the rate of digestion. Profitability was similar for all prey sizes over the duration of the period of observation, and thus did not correspond to diet composition. Rejection of prey after brief manipulation, a proposed mechanism for optimal foraging in the predator $C$ maenas, was not observed in the present study. Nevertheless, size selection was marked.
\end{abstract}

\section{INTRODUCTION}

The selection of intermediate-sized mussels Mytilus edulis by shore crabs Carcinus maenas (Elner \& Hughes 1978) is one of the most convincing demonstrations of optimal foraging. The authors observed that crabs rejected suboptimal (large and small) mussels after a brief period of manipulation, termed 'recognition time', suggesting that they could evaluate profitability (defined as yield of flesh per unit handling time) from tactile cues. Hughes (1979) showed that modification of optimal foraging theory to include recognition time could explain the inclusion of suboptimal prey in the diet as their abundance increased, contrary to previous predictions (Pyke et al. 1977). The behavioural basis of the size preferences shown by $C$. maenas for $M$. edulis was investigated by Jubb et al. (1983), whose results confirmed in general those of Elner \& Hughes (1978). However, some new observa- tions, such as the rejection of a certain number of optimal prey, were difficult to explain. As a possible alternative to the original prey-evaluation hypothesis, Jubb et al. (1983) proposed the relative-stimulus hypothesis, where acceptance or rejection of a mussel held in the chelae depends on the relative strengths of stimuli from the grasped mussels and those simultaneously touched by the periopods. Both these hypotheses predict a preponderance of optimal prey in the diet, but neither completely explains the observed results (Jubb et al. 1983).

Carcinus maenas preying on dogwhelks Nucella lapillus attacked all prey as encountered, but small prey were sometimes dropped accidentally while very large ones were rejected after unsuccessful breaking attempts. Thus optimal intermediate-sized prey again predominated in the diets. The differing foraging tactics for mussels and dogwhelks were considered to be appropriate to their distribution and morphology, mus- 
sels occurring in patches at high densities and having a more predictable prey value than the sparsely-distributed dogwhelks, the shells of which apparently vary considerably in robustness (Hughes \& Elner 1979).

Blue crabs Callinectes sapidus, feeding on mussels Geukensia demissa, accepted the smallest, most profitable prey when encountered but frequently rejected larger prey which were more difficult to open. The recognition of large suboptimal prey was often reduced after a few minutes' experience from manipulation by the mouthparts, lasting at least several seconds, to an instantaneous touch by a walking leg. Size selection, resulting from an active choice by the predator, could be based on energy maximization or on time minimization. Small Inussels were optimal for this crab species because the chelae are finer and more dextrous than those of Carcinus maenas, enabling efficient gleaning of flesh from small prey (Hughes \& Seed 1981).

This paper presents a study of size-selective behaviour by the portunid crab Liocarcinus puber (L.) feeding on mussels Mytilus edulis L. and on juvenile shore crabs Carcinus maenas (L.). The handling methods used by $L$. puber for these prey are described by ap Rheinallt \& Hughes (1985). L. puber inhabits rocky sublittoral areas in the U.K. and Europe, extending up to the lower shore (Christiansen 1969, Ingle 1980), where it may coexist with C. maenas (pers. obs., Crothers 1970). In the field, $L$. puber is known to feed on both mussels and crustaceans (González Gurriarán 1978). While many other portunid crabs include both molluscs and crustaceans in their diets (Darnell 1958, Ropes 1968, Tagatz 1968, Hill 1976, 1979, Paul 1981, Williams 1982), no published study has investigated size selection of active mobile prey by crabs.

Laboratory experiments were designed to answer the following questions. (1) Which sizes of Mytilus edulis predominate in the diet of Liocarcinus puber? (2) Is the choice of prey sizes related to profitability? (3) What are the mechanisms that lead to size selection? (4) How does size selection by this species compare with that of Carcinus maenas feeding on mussels? (5) What is the nature of size selection by $L$. puber on mobile prey (juvenile $C$. maenas)?

\section{METHODS}

Liocarcinus puber, collected from baited pots at various sites on the Llŷn Peninsula, Gwynedd, North Wales, were held individually in $23 \times 43 \mathrm{~cm}$ clear plastic aquaria in a recirculating seawater system under fluorescent lights on manual control.

Ten female Liocarcinus puber, carapace width 7 to $8 \mathrm{~cm}$, were divided into 2 groups of 5 individuals. One group was fed a diet of small Carcinus maenas for $7 \mathrm{~d}$ and the other a diet of Mytilus edulis for the same period. They were then starved for $72 \mathrm{~h}$ to standardize hunger level, and presented with mixtures of different sizes of the prey species on which they were accustomed to feed, at $72 \mathrm{~h}$ intervals. Each trial lasted $4 \mathrm{~h}$; predation was observed continuously for the first $2 \mathrm{~h}$ and prey replaced as eaten. After $3 \mathrm{~h}$ prey were counted and those eaten were replaced; prey were again counted at the end of the trial. The order of presentation of the prey mixtures to each crab was randomized. Each mixture of prey sizes was presented once to each of the 5 individual L. puber.

Pilot studies indicated the approximate maximum number of prey which could be presented, while permitting accurate recording of all contacts between predator and prey.

During the periods of continuous observation, the occurrence of the following events was recorded with the aid of a stopwatch. (1) Contact of prey with the chelae, periopods, or abdomen of Liocarcinus puber. (2) Successful and unsuccessful attempts to grasp prey (3) Handling times, as described by ap Rheinallt \& Hughes (1985). (4) The duration of unsuccessful breaking attempts on mussels. (5) Accidental dropping of prey. (6) Deliberate rejection of prey. (7) The proportion of prey flesh ingested, estimated visually to the nearest $10 \%$.

Although the distinction between dropping and rejection was subjective, preliminary trials had suggested that instances when crabs opened the chelae, thus releasing the grasped prey, or placed it on the floor of the tank before pushing it aside with a chela (6) were distinguishable from dropping of the prey, usually when it was not firmly grasped, followed by scrabbling with the periopods in an effort to retrieve it (5). Doubtful cases were referred to Category (5).

The numbers of larger and smaller prey contacted during the period of observation, and the total numbers eaten, were compared with the ratios expected from the numbers presented ( $G$ statistic, 1 df; Sokal \& Rohlf 1981, p. 695).

The proportions of larger and smaller prey contacted that were ignored, and the success of grasping attempts, as well as the proportions of grasped prey of each size that were subsequently eaten, dropped, or rejected, were compared using the observed frequencies in 2 by 2 contingency tables ( $G$ statistic, $1 \mathrm{df}$ ). The fate of some prey, still held uneaten in the chelae at the end of the period of observation, was not determined.

Using the handling time data obtained from the experiments, the profitability $\left(\mathrm{P}, \mathrm{J} \mathrm{s}^{-1}\right)$ of each prey size class was calculated as:

$$
\mathrm{P}=\mathrm{CSF} / \mathrm{H}
$$


where $\mathrm{C}=$ energy content of the prey flesh, $19500 \mathrm{~J}$ $\mathrm{g}^{-1}$ for mussels (Elner \& Hughes 1978) and $23700 \mathrm{~J} \mathrm{~g}^{-1}$ for juvenile shore crabs (Klein Breteler 1975); $\mathrm{S}=$ mean proportion of prey flesh eaten; $F=$ mean flesh dry weight of prey from the given size class, calculated from the regressions below; $\mathrm{H}=$ mean handling time of eaten prey from the size class under consideration.

Profitabilities $\left(P_{1}\right.$ and $\left.P_{2}\right)$ of 2 prey sizes presented together were then compared.

and

$$
\begin{gathered}
\text { If } \mathrm{P}_{1}=\mathrm{P}_{2} \text {, then } \\
\mathrm{S}_{1} \mathrm{~F}_{1} / \mathrm{H}_{1}=\mathrm{S}_{2} \mathrm{~F}_{2} / \mathrm{H}_{2} \\
\mathrm{H}_{1}-\mathrm{H}_{2}\left(\mathrm{~S}_{1} \mathrm{~F}_{1} / \mathrm{S}_{2} \mathrm{~F}_{2}\right)=0
\end{gathered}
$$

In order to estimate $95 \%$ confidence limits for this quantity, Bonferroni's method of multiple comparisons (Neter \& Wasserman 1974) was applied to the results of analyses of variance of handling time according to prey size and crab identity. Where the confidence limits do not enclose zero, profitabilities of the 2 prey sizes differ significantly. Errors arise through ignoring variability in $F$ within a prey size class, but these are Type 2 rather than Type 1 errors since, within a prey size class, large $F$ will tend to be associated with long $\mathrm{H}$. Errors could also arise from the visual estimation of $S$; however, except for large shore crabs, nearly all prey were completely consumed.

The above method of calculating profitability is inappropriate when involvement time with prey not consumed is significant. This was so only for large mussels, for which profitabilities were recalculated including this involvement time in $\mathrm{H}$. Profitability is now given by:

$$
\mathrm{P}=\mathrm{NCSF} / \mathrm{T}
$$

where $\mathrm{N}=$ number of prey eaten; $\mathrm{T}=$ total involvement time with eaten and uneaten prey from the size class under consideration.

Mytilus edulis prey. Mussels were collected from the supporting structures of Bangor Pier (Ordnance Survey map reference SH584733). The dry flesh weight $(\mathrm{y}, \mathrm{g})$ was related to the shell length $(x, c m)$ by the regression:

$$
\log _{e} y=3.28 \log _{e} x-5.69 \quad n=200, r=0.97(4)
$$

Only mussels maintained in captivity for less than $21 \mathrm{~d}$ were used, since shells became brittle and flesh content fell after longer periods.

Each individual Liocarcinus puber was presented with 6 mixtures of mussel sizes. Four shell length categories of mussels were used: very small (VS), 1.0 to $1.25 \mathrm{~cm}$; small (S), 1.5 to $1.75 \mathrm{~cm}$; medium (M), 2.25 to $2.5 \mathrm{~cm}$; large (L), 2.75 to $3 \mathrm{~cm}$. The mixtures presented were: 10VS/10S; 10VS/5S; 10S/10M; 10S/5M; 10M/5L; $5 \mathrm{M} / 5 \mathrm{~L}$. When the 2 smallest prey sizes were presented together, predation was very rapid, and thus each trial lasted $2 \mathrm{~h}$ only, with continuous observation for the first hour.

The water temperature during the experiments varied between 12.4 and $16.0^{\circ} \mathrm{C}$

Carcinus maenas prey. Small specimens of Carcinus maenas were collected from the shore at Gorad, Bangor (SH574726). The ash-free dry weight (y, g), incorporating a correction for weight loss of $\mathrm{CaCO}_{3}$ during combustion (Klein Breteler 1975), was related to the carapace width $(\mathrm{x}, \mathrm{cm})$ by the regression:

$$
\log _{e} \mathrm{y}=2.68 \log _{\mathrm{e}} \mathrm{x}-3.24 \quad \mathrm{n}=89, \mathrm{r}=0.95
$$

Each individual Liocarcinus puber was presented with 4 mixtures of prey sizes. Three carapace width categories of shore crabs were used: small (S), 0.8 to $0.9 \mathrm{~cm}$; medium (M), 1.1 to $1.2 \mathrm{~cm}$; large (L), 1.5 to $1.6 \mathrm{~cm}$. The mixtures presented were: $10 \mathrm{~S} / 10 \mathrm{M}_{\mathrm{i}}$ $10 \mathrm{~S} / 5 \mathrm{M} ; 10 \mathrm{M} / 5 \mathrm{~L} ; 5 \mathrm{M} / 5 \mathrm{~L}$

The water temperature during the experiments varied between 11.4 and $13.4^{\circ} \mathrm{C}$.

\section{RESULTS}

Handling procedures for Mytilus edulis and Carcinus maenas were similar to those observed when prey were presented singly (ap Rheinallt \& Hughes 1985). Contacts with several prey simultaneously were frequent, and resulted in brief and apparently indiscriminate attempts to pick them up using the chelae and periopods. However, no more than 2 prey could usually be held at once, 1 of these frequently being dropped during manipulation. Shore crabs that were dropped usually escaped into a corner of the aquarium.

\section{Mytilus edulis prey}

Size composition of diets

Significantly more small than very small prey, and significantly more medium than large prey were eaten, relative to the numbers presented. The difference between medium and small prey was not significant (Table 1).

The relative numbers contacted did not differ significantly from those presented in any of the $6 \mathrm{mix}$ tures. Many prey contacts evoked no grasping attempts: in 3 of the 6 mixtures significantly more contacts with smaller than with larger prey were thus ignored. The success of grasping attempts on larger prey was significantly higher than on smaller prey in 3 of the 6 mixtures (Table 2).

A significantly higher percentage of medium prey 
contacted were grasped in the $10 \mathrm{~S} / 5 \mathrm{M}$ mixture than in the $10 \mathrm{~S} / 10 \mathrm{M}$ mixture $(\mathrm{G}=5.18, \mathrm{df}=1, \mathrm{P}<0.05)$. A significantly higher percentage of large mussels con-

Table 1. Liocarcinus puber and Mytilus edulis prey. Numbers eaten of the larger prey, expressed as percentage of total number of larger and smaller prey eaten in each mixture; expected percentages based on ratios in which prey of the 2 sizes were presented; values of the $G$ statistic $(1 \mathrm{df})$ for the differences between observed numbers and expected values; probabilities that these differences were due to chance

\begin{tabular}{|lccc|}
\hline Mixture & Observed & Expected & $\mathrm{G}$ \\
\hline $10 \mathrm{VS} / 10 \mathrm{~S}$ & 62 & 50 & $7.14^{\circ}$ \\
$10 \mathrm{VS} / 5 \mathrm{~S}$ & 42 & 33 & $4.45^{\circ}$ \\
$10 \mathrm{~S} / 10 \mathrm{M}$ & 60 & 50 & 3.59 \\
$10 \mathrm{~S} / 5 \mathrm{M}$ & 39 & 33 & 1.02 \\
$10 \mathrm{M} / 5 \mathrm{~L}$ & 18 & 33 & $5.06^{\circ}$ \\
$5 \mathrm{M} / 5 \mathrm{~L}$ & 29 & 50 & $5.96^{\circ}$ \\
& & & \\
$\mathrm{P}<0.05$ & $\cdots \mathrm{P}<0.01$ & & \\
\hline
\end{tabular}

tacted were grasped in the $5 \mathrm{M} / 5 \mathrm{~L}$ mixture than in the $10 \mathrm{M} / 5 \mathrm{~L}$ mixture $(\mathrm{G}=12.49 \mathrm{df}=1, \mathrm{P}<0.001)$. No significant differences existed between the 2 densities of each combination of prey sizes in the proportion of grasped prey that were subsequently eaten, dropped or rejected, and data were therefore combined for analysis.

A significantly higher percentage of medium than of large mussels that had been grasped were subsequently eaten. Few mussels were dropped or rejected when the 2 smallest prey sizes were presented together. But significantly more small than medium mussels were dropped when these 2 sizes were presented together. The percentage rejected increased with prey size, with significant differences between medium and small prey, and large and medium prey, in the respective mixtures (Table 3 ).

There was significant variation among the 5 individual Liocarcinus puber in the total number of mussels eaten in all trials pooled together $(G=32.10$, $\mathrm{df}=4, \mathrm{P}<0.001$ ).

Table 2. Liocarcinus puber and Mytilus edulis prey. Numbers of smaller (s) and larger (1) prey contacted; values of the G statistic (1 df) for the differences between observed numbers and those expected from the ratios in which prey of the 2 sizes were presented; probabilities that these differences were due to chance. Percentages of smaller and larger prey contacted that were

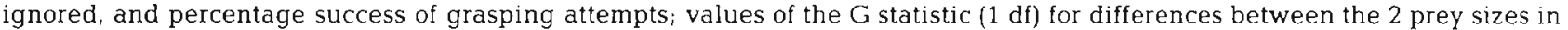
the proportions of contacts that were ignored and of grasping attempts that succeeded; probabilities that these differences were due to chance

\begin{tabular}{|c|c|c|c|c|c|c|c|c|c|}
\hline \multirow[t]{2}{*}{ Mixture } & \multicolumn{3}{|c|}{ Contacted } & \multicolumn{3}{|c|}{ Ignored } & \multicolumn{3}{|c|}{ Grasped } \\
\hline & s & 1 & $\mathrm{G}$ & $\mathrm{s}$ & 1 & G & s & 1 & $G$ \\
\hline $10 \mathrm{VS} / 10 \mathrm{~S}$ & 94 & 99 & 0.14 & 52 & 39 & 3.16 & 56 & 78 & $6.19^{\circ}$ \\
\hline $10 \mathrm{VS} / 5 \mathrm{~S}$ & 146 & 68 & 0.24 & 52 & 35 & $5.31^{\circ}$ & 54 & 66 & 1.51 \\
\hline $10 \mathrm{~S} / 10 \mathrm{M}$ & 110 & 138 & 3.16 & 62 & 51 & 3.06 & 57 & 78 & $5.27^{\circ}$ \\
\hline $10 \mathrm{~S} / 5 \mathrm{M}$ & 104 & 41 & 1.71 & 51 & 24 & $8.40^{\circ}$ & 67 & 77 & 1.12 \\
\hline $10 \mathrm{M} / 5 \mathrm{~L}$ & 139 & 65 & 0.19 & 39 & 38 & 0.01 & 72 & 73 & 0.02 \\
\hline $5 \mathrm{M} / 5 \mathrm{~L}$ & 81 & 79 & 0.02 & 47 & 22 & $11.66^{\cdots} \cdots$ & 67 & 94 & $12.29 \cdots$ \\
\hline$\cdot P<0.05$ & $\cdots P<0.01$ & & 0.001 & & & & & & \\
\hline
\end{tabular}

Table 3. Liocarcinus puber and Mytilus edulis prey. Numbers of smaller (s) and larger (1) prey grasped that were subsequently eaten, dropped, or rejected, expressed as percentage of numbers grasped in each mixture; values of the G statistic (1 df) for differences between the 2 prey sizes in the proportions that were eaten, dropped, and rejected; probabilities that these differences were due to chance

\begin{tabular}{|c|c|c|c|c|c|c|c|c|c|}
\hline \multirow[t]{2}{*}{ Mixture } & \multicolumn{3}{|c|}{ Eaten } & \multicolumn{3}{|c|}{ Dropped } & \multicolumn{3}{|c|}{ Rejected } \\
\hline & s & 1 & G & s & 1 & $\mathrm{G}$ & s & 1 & G \\
\hline VS/S & 86 & 87 & 0.04 & 11 & 14 & 0.02 & 2 & 1 & 0.01 \\
\hline $\mathrm{S} / \mathrm{M}$ & 62 & 57 & 0.32 & 28 & 13 & $4.48^{\circ}$ & 5 & 21 & $7.35^{*}$ \\
\hline $\mathrm{M} / \mathrm{L}$ & 37 & 11 & $15.92 \cdots$ & 40 & 37 & 0.20 & 21 & 45 & $11.46^{\cdots} \cdots$ \\
\hline$\cdot P<0.05$ & $\cdots P<0.01$ & & $P<0.001$ & & & & & & \\
\hline
\end{tabular}


Handling times and prey profitabilities

Analyses of variance showed that handling times differed significantly between prey sizes presented together, being longer for the larger prey $(\mathrm{F}=77.41$, $\mathrm{df}=1,141, \mathrm{P}<0.001$ for very small and small prey; $\mathrm{F}=143.16, \quad \mathrm{df}=1,161, \quad \mathrm{P}<0.001$ for small and medium prey; $F=24.12, \quad d f=1,75, \quad P<0.001$ for medium and large prey). Mean handling times for individual Liocarcinus puber ranged from 133 to $190 \mathrm{~s}$ (VS prey), 270 to $441 \mathrm{~s}$ (S), 613 to $1681 \mathrm{~s}(\mathrm{M})$, and 1001 to $2873 \mathrm{~s}(\mathrm{~L})$.

When prey sizes were considered separately, handling times differed significantly among individual Liocarcinus puber for small prey $(\mathrm{F}=5.15, \mathrm{df}=4,92$, $P<0.001), \quad$ medium prey $(F=6.74, \quad$ df $=4,69$, $P<0.001)$, and large prey $(F=5.31, d f=3,6$, $P<0.05$ ). Flesh was thoroughly gleaned from all but 5 of the 231 mussels observed to be eaten. Handling time was not significantly correlated with the amount of flesh already consumed, but it did vary considerably among individual prey in a size class.

Small prey were significantly more profitable than very small prey for 4 Liocarcinus puber. Otherwise, the order of profitability was more variable, although medium prey were significantly more profitable than small prey for 1 L. puber, and significantly more profitable than large prey for another. When the time spent on unsuccessful breaking attempts was included in the calculation of profitability, the profitability of large mussels was always reduced to below that of medium ones. One $L$. puber did not break open any large prey (Table 4).

\section{Carcinus maenas prey}

Size composition of diets

In all 4 mixtures, the larger of the 2 prey sizes presented predominated in the diets, numbers eaten differing significantly from the ratios presented (Table 5).
The numbers of prey contacted differed at a high level of significance from the expected ratios, based on the numbers presented, when small and medium shore crabs were presented together, but not when medium and large shore crabs were presented. As with mussels, contacts with some shore crab prey were ignored, but in only 1 of the 4 mixtures was there a significant difference between prey sizes in the proportion of contacts that resulted in grasping attempts. During

Table 4. Liocarcinus puber and Mytilus edulis prey. Profitabilities $\left(\mathrm{J} \mathrm{s}^{-1}\right)$ of mussel size classes to individual $L$. puber (identified by crusher chela height, cm). (1) Profitabilities calculated using the time spent on successful attacks only; profitabilities linked by asterisks are significantly different $(P<0.05)$. (2) Profitabilities of medium and large prey when time spent attempting unsuccessfully to break them open is also included

\begin{tabular}{|cccccccc|}
\hline Crab & \multicolumn{3}{c}{1} & \multicolumn{3}{c}{2} \\
& VS & S & M & L & M & L \\
\hline 1.73 & 0.63 & 0.76 & 0.68 & - & 0.45 & 0.00 \\
1.76 & $0.55 \cdot 0.98$ & $1.15 \cdot$ & 0.74 & 0.92 & 0.52 \\
1.80 & $0.73 \cdot 1.13$ & 1.35 & 1.47 & 1.32 & 0.38 \\
1.83 & $0.78 \cdot 1.20$ & 1.42 & 2.13 & 1.40 & 1.19 \\
2.06 & $0.77 \cdot 1.23 \cdot 1.87$ & 1.74 & 1.87 & 1.33 \\
\hline
\end{tabular}

Table 5. Liocarcinus puber and Carcinus maenas prey. Numbers eaten of the larger prey, expressed as percentages of total numbers of prey eaten in each mixture. Notation and analysis as in Table 1

\begin{tabular}{lccc|}
\hline Mixture & Observed & Expected & $\mathrm{G}$ \\
\hline $10 \mathrm{~S} / 10 \mathrm{M}$ & 80 & 50 & $20.22 \cdots$ \\
$10 \mathrm{~S} / 5 \mathrm{M}$ & 63 & 33 & $22.56 \cdots$ \\
$10 \mathrm{M} / 5 \mathrm{~L}$ & 75 & 33 & $23.21 \cdots$ \\
$5 \mathrm{M} / 5 \mathrm{~L}$ & 85 & 50 & $14.77 \cdots$ \\
$\ldots P<0.001$ & & & \\
\hline
\end{tabular}

Table 6. Liocarcinus puber and Carcinus maenas prey. Numbers of smaller (s) and larger (l) prey contacted, percentages of contacts that were ignored, and percentage success of grasping attempts. Notation and analysis as in Table 2

\begin{tabular}{|c|c|c|c|c|c|c|c|c|c|}
\hline \multirow[t]{2}{*}{ Mixture } & \multicolumn{3}{|c|}{ Contacted } & \multicolumn{3}{|c|}{ Ignored } & \multicolumn{3}{|c|}{ Grasped } \\
\hline & s & 1 & $\mathrm{G}$ & s & 1 & $\mathrm{G}$ & s & 1 & G \\
\hline $10 \mathrm{~S} / 10 \mathrm{M}$ & 151 & 251 & $25.14 \cdots$ & 30 & 25 & 1.16 & 14 & 28 & $7.86^{\cdots}$ \\
\hline $10 \mathrm{~S} / 5 \mathrm{M}$ & 171 & 131 & $13.16^{\cdots}$ & 14 & 15 & 0.01 & 22 & 37 & $6.20^{\circ}$ \\
\hline $10 \mathrm{M} / 5 \mathrm{~L}$ & 285 & 153 & 0.49 & 28 & 10 & $19.13^{\cdots} \cdots$ & 9 & 27 & $20.04 \cdots$ \\
\hline $5 \mathrm{M} / 5 \mathrm{~L}$ & 103 & 120 & 1.29 & 21 & 28 & 1.13 & 9 & 30 & $12.69 \cdots$ \\
\hline$\cdot P<0.05$ & $\cdots P<0.01$ & & $P<0.001$ & & & & & & \\
\hline
\end{tabular}


these attempts, Liocarcinus puber was clearly more successful at grasping prey of the larger size (Table 6)

Significantly higher proportions of small prey contacted $(\mathrm{G}=12.84$, df $=1, \mathrm{P}<0.001)$ and of medium prey contacted $(\mathrm{G}=6.43, \mathrm{df}=1, \mathrm{P}<0.05)$ were ignored in the $10 \mathrm{~S} / 10 \mathrm{M}$ trials than in the $10 \mathrm{~S} / 5 \mathrm{M}$ trials. More large prey were ignored in the $5 \mathrm{M} / 5 \mathrm{~L}$ than in the $10 \mathrm{M} / 5 \mathrm{~L}$ trials $(\mathrm{G}=13.28$, df $=1, \mathrm{P}<0.001)$. No significant difference existed between the 2 densities of each combination of prey sizes in the proportion of grasped prey that were subsequently eaten or dropped, and data were therefore combined for analysis.

Only 3 shore crabs were observed to be rejected in $40 \mathrm{~h}$ of observation. Many were dropped, apparently by accident, or escaped from the grasp of the predator; a significantly higher proportion of small than of medium prey, and of medium than of large prey, were dropped. However, there was no significant difference between prey sizes in the proportion of grasped prey that were observed to be eaten, because uneaten larger prey were frequently held in the chelae at the end of the period of observation (Table 7 ).

The total number of shore crabs eaten in all trials pooled together did not differ significantly among the 5 individual Liocarcinus puber $(\mathrm{G}=3.30$, $\mathrm{df}=4$, $\mathrm{P}>0.05)$.

Handling times and prey profitabilities

In analyses of variance, handling times did not differ significantly among individual Liocarcinus puber for any prey size ( $P>0.05$ in each case). Handling times differed significantly between pairs of prey sizes presented together, being longer for the larger prey size $(\mathrm{F}=12.53, \mathrm{~d} f=1,84, \mathrm{P}<0.001$ for small and medium prey; $\mathrm{F}=23.66, \mathrm{df}=1,90, \mathrm{P}<0.001$ for medium and large prey). Mean handling times for individual $L$. puber ranged from 185 to $343 \mathrm{~s}$ (S prey), 560 to $606 \mathrm{~s}$ (M), and 937 to $1413 \mathrm{~s}(\mathrm{~L})$.

The majority of shore crab prey were completely consumed, and for only 4 of 125 observed prey was the estimated proportion of flesh consumed less than 0.7 .

Table 7. Liocarcinus puber and Carcinus maenas prey. Numbers of smaller (s) and larger (l) prey eaten or dropped, expressed as percentages of the numbers grasped. Notation and analysis as in Table 3, but rejected prey omitted because of their low numbers (see text)

\begin{tabular}{|c|c|c|c|c|c|c|}
\hline \multirow[t]{2}{*}{ Mixtures } & \multicolumn{3}{|c|}{ Eaten } & \multicolumn{3}{|c|}{ Dropped } \\
\hline & $s$ & 1 & $G$ & 5 & 1 & $\mathrm{G}$ \\
\hline $\mathrm{S} / \mathrm{M}$ & 54 & 62 & 0.75 & 44 & 23 & $6.07^{\circ}$ \\
\hline$M / L$ & 36 & 52 & 1.95 & 64 & 27 & $10.29^{\circ}$ \\
\hline$\cdot P<0.05$ & \multicolumn{6}{|c|}{$\therefore P<0.01$} \\
\hline
\end{tabular}

Mean proportions ingested were $0.98(\mathrm{~S}), 0.96(\mathrm{M})$, and 0.88 (L). Because handling times did not differ significantly among individual predators a single value of profitability for each prey size class was calculated. Mean profitabilities (in $\mathrm{J} \mathrm{s}^{-1}$ ) were 2.22 (S), 2.25 (M), and 2.23 (L), with no significant differences among sizes.

As more prey were eaten, handling times lengthened and profitabilities fell. Regression lines of the profitability of each prey consumed, estimated from the handling time and the proportion of flesh eaten, on the amount of energy already ingested, were calculated. The negative correlation between profitability and energy already ingested was significant for large and medium prey, but not for small prey (Fig. 1). The regression relations did not differ significantly among prey sizes, profitabilities being very variable within each size class (analysis of covariance: $\mathrm{F}=2.43 \mathrm{df}=$ $2,119, \quad P=0.09$ for slopes; $F=1.46, \quad d f=2,121$, $\mathrm{P}=0.24$ for adjusted means). There was no significant correlation of the angular transformation of the proportion of prey flesh eaten with the weight of dry flesh already ingested, or with handling time.

\section{DISCUSSION}

\section{Handling times and profitabilities}

Within the size range presented, mean profitabilities of Mytilus edulis prey ranged from 0.5 to $1.9 \mathrm{~J} \mathrm{~s}^{-1}$, while profitabilities of Carcinus maenas were 3 to 5 $\mathrm{J} \mathrm{s}^{-1}$ for hungry Liocarcinus puber. However, handling

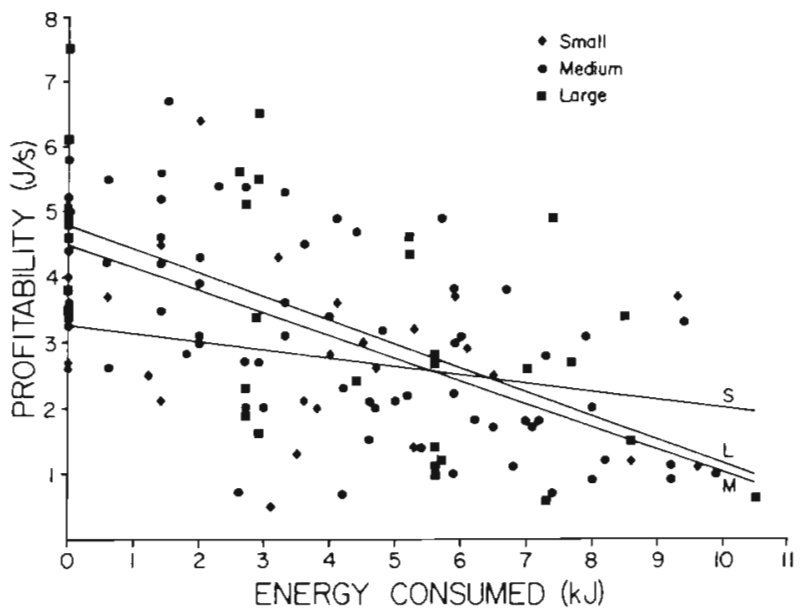

Fig. 1. Liocarcinus puber and Carcinus maenas prey. Profitability $\left(\mathrm{P}, \mathrm{J} \mathrm{s}^{-1}\right)$ of each prey plotted against the quantity of energy already ingested during the trial (W, kJ) with calculated regressions for each prey size (see text). ( $\bullet$ Small prey $(\mathrm{P}=3.28-0.13 \mathrm{~W}, \mathrm{n}=25, \mathrm{r}=-0.27, \mathrm{P}=0.19)_{;}(\bullet)$ medium prey $(\mathrm{P}=4.55-0.35 \mathrm{~W}, \mathrm{n}=67, \mathrm{r}=-0.64, \mathrm{P}<0.001)$; $(\boldsymbol{\square})$ large prey $(P=4.78-0.36 \mathrm{~W}, \mathrm{n}=33, \mathrm{r}=-0.63, \mathrm{P}<0.001)$ 
times of shore crabs, unlike mussels, lengthened as more food was ingested, so that the profitabilities fell to about 1 to $2 \mathrm{~J} \mathrm{~s}^{-1}$. During predation on mussels, individual differences among predators were important: the total weight of dry flesh ingested by the crab with the largest crusher chela (height $2.06 \mathrm{~cm}$ ) was 3 times that ingested by the crab with the smallest crusher (height $1.73 \mathrm{~cm}$ ). When L. puber fed on shore crabs, however, individual differences in the number of prey eaten during experiments were not significant, and individual consumption varied by a factor of only 1.4 .

These differences can be explained in terms of the differing morphologies of the 2 prey species. The resistant outer shell sets a mechanical upper size limit to predation on mussels, and because the shell must be broken in order to gain access to the comparatively small amount of flesh contained within, profitabilities are initially lower than those of shore crabs. On the other hand, Liocarcinus puber, while it can easily break up shore crab prey, does not separate flesh and exoskeleton prior to ingestion. Thus as more flesh is consumed, the cardiac stomach fills up with pieces of exoskeleton, which are broken down slowly. Ingestion decelerates, being perhaps limited by the rate of digestion, and profitability becomes low and similar for all prey sizes. Once the shell of a mussel is broken, however, the soft and easily digested flesh is freely available. Handling times do not lengthen and profitability remains constant. Assimilation of energy from ingested prey was not examined in the present study, but it is probable that assimilation of mussel flesh is faster and more complete, thus increasing the value of mussels as prey compared with shore crabs.

Individual differences in handling times, profitabilities, and numbers eaten testify to the importance of the crusher chela in breaking open mussels, as described by ap Rheinallt \& Hughes (1985). Smaller individuals could perhaps forage more efficiently by concentrating on other prey. A number of studies have shown that female and young crabs eat more softbodied prey and fewer molluscs than larger-clawed males (Darnell 1958, Ropes 1968, Tagatz 1968, González Gurriarán 1978).

Incomplete consumption of shore crabs is perhaps related to the filling of the digestive tract and the lengthening of handling times over the period of observation.

\section{Size selection}

\section{Mytilus edulis}

The number of contacts with different-sized mussels was in close agreement with the ratios presented, as would be expected for a predator which is large relative to the prey and responds to contact of prey with the chelae, periopods and body surface (ap Rheinallt 1982)

The predominance of medium-sized mussels in the diets was due to 3 factors acting in favour of the consumption of larger prey and 1 factor mediating against it. Smaller prey were more difficult to grasp, easier to drop, and contacts with them were ignored more frequently. Some large and medium prey were rejected after unsuccessful breaking attempts.

Hungry crabs responded to contacts with mussels of all sizes when these were presented singly (ap Rheinallt \& Hughes 1985). In the present case, Liocarcinus puber seldom responded to contacts while ingesting flesh. Large prey apparently provided stronger tactile stimuli than small ones, leading more frequently to grasping attempts. Fewer small mussels were ignored in the VS/S trials than in the S/M trials, when large fragments of eaten medium prey tended to obscure small prey. A similar phenomenon was described for Callinectes sapidus feeding on Geukensia demissa (Hughes \& Seed 1981).

Ap Rheinallt \& Hughes (1985) found that the time required for Liocarcinus puber to pick up mussels presented singly was negatively correlated with prey size, suggesting that large mussels were easier to pick up because of the limited dexterity of the chelae in dealing with smaller prey. In the present study simultaneous contacts with prey were frequent, and crabs attempting to pick up many prey at once retained the larger individuals while the smaller ones fell out of their grasp.

The accidental dropping of prey usually took place when 2 (occasionally 3) prey were held in the chelae. Crabs could hold 2 small or very small prey, 1 in each chela, and attempt to break 1 of these using the mouthparts for support. But both chelae were needed to hold and to break open larger prey, and only during the later stages of eating could a second mussel be retained in the grasp without being dropped. So the number of prey dropped was lowest in the VS/S trials and highest in the $M / L$ trials. Limited chelal dexterity accounts for the higher proportion of small than of medium prey dropped.

The rejection of prey after unsuccessful breaking attempts was usually in response to contacts with other prey, as proposed by the relative-stimulus hypothesis of Jubb et al. (1983). Liocarcinus puber could open prey larger than those presented using 'edge-chipping' if these prey were presented singly, although handling time was then very long (ap Rheinallt 1982). Limited persistence time could provide a mechanism which adjusts predation to varying prey densities, with timeconsuming large prey being eaten only when other 
prey are scarce. It also results in predation on the least resistant individuals within a size class (Jubb et al. 1983).

\section{Carcinus maenas}

The preponderance of larger prey in the diets of Liocarcinus puber was due to 2 factors, a higher rate of contact with larger prey and a higher rate of success when attempts to grasp them were made. Small prey, less active than larger ones, were contacted less frequently.

Compared to mussels, fewer contacts with prey were ignored: mobile shore crabs seemed to provide a strong stimulus for attack irrespective of their size.

As with shore crabs presented singly (ap Rheinallt \& Hughes 1985) and with mussels, larger prey were grasped more easily by the chelae than smaller ones. This was particularly evident when several prey were contacted simultaneously and the predator scrabbled with periopods and chelae in an attempt to capture them. Similarly, smaller prey were more likely to escape during manipulation, particularly when more than 1 prey was held. However, in the experiments this tendency was countered by the retention of uneaten larger prey in the chelae at the end of the period of observation.

\section{Relation to optimal foraging theory and comparisons with foraging strategy of Carcinus maenas}

Some recent work has suggested that, because handling time data are frequently very variable and several different curves can be fitted to them, calculated curves may be inappropriate for the interpretation of the results of size-selection experiments (Lawton \& Hughes 1985). In the present study, however, some significant differences in profitabilities between size classes of Mytilus edulis did exist, in spite of the variable nature of handling time. The large individual variation in the amount of biomass consumed during the experiments suggests that these differences could be important for crabs foraging in the field. The ranking of individuals according to chela size corresponded closely to the order of profitabilities within each prey size class (Table 4) and corresponded exactly to the ranking according to the number of prey eaten. In addition, those crabs with larger chelae spent less total time feeding.

The relative numbers of different-sized mussels eaten correspond closely to their mean profitabilities (Fig. 2). This is because the same factors affect both profitability and numbers eaten. Because of the limited dexterity of the chelae, Liocarcinus puber has difficulty picking up small mussels and retaining them in its grasp, and gleans flesh from them inefficiently. The upper limit to chela strength lowers the success of attacks on large prey and retards handling of those large prey which are attacked successfully. Thus prey size-selection is a consequence of the mechanical factors which also determine profitability.

No upper size limit to predation on shore crabs existed within the size range used in the experiments. As hunger decreased, profitabilities of all prey sizes fell, and were almost identical for all prey sizes over the duration of the period of observation, but attack and retention of the smaller prey continued to be inefficient. Thus the numbers eaten do not correspond to profitability for this prey species, the involvement time with smaller prey attacked unsuccessfully having no appreciable effect on profitability because of its short duration.

In contrast to Carcinus maenas feeding on Mytilus edulis (Elner \& Hughes 1978, Jubb et al. 1983) and to Callinectes sapidus feeding on Geukensia demissa (Hughes \& Seed 1981), Liocarcinus puber only very rarely rejected mussels after a brief period of manipulation, but did reject some large mussels after unsuccessful breaking attempts. The observed foraging strategy of $L$. puber on mussels resembles instead that of C. maenas feeding on Nucella lapillus (Hughes \& Elner 1979). However, it is possible that rejection occurs at higher prey densities than those used in the present experiments, where differences between densities did not show a consistent pattern.

The effects of accidental dropping of prey las

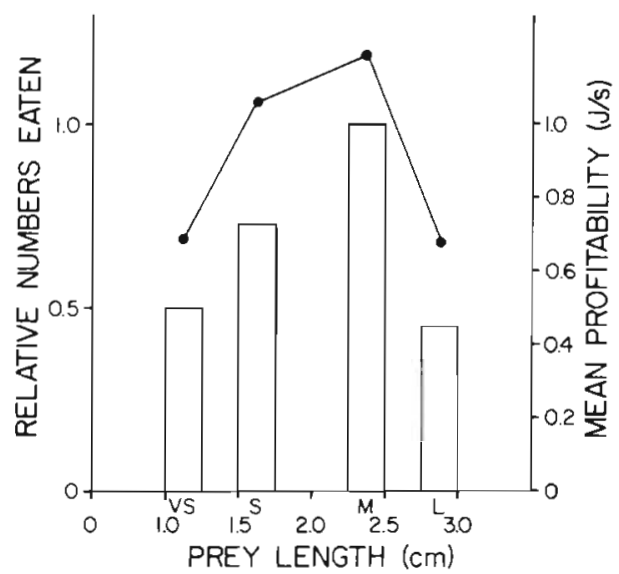

Fig. 2. Liocarcinus puber and Mytilus edulis prey. Mean profitabilities ( ) of prey, including time spent on unsuccessful breaking attempts, calculated from values in Table 4. Also relative numbers of prey eaten (histograms) calculated for each combination of prey sizes as: total numbers eaten/total numbers presented in all 10 trials ( 2 densities, 5 crabs). The 3 ratios thus obtained (VS:S, S:M, M : L) are presented relative to an arbitrary value of 1 for medium prey 
defined in the present study) and of their rejection (as defined by Elner \& Hughes 1978) are different: the smallest mussels were frequently rejected by Carcinus maenas (Elner \& Hughes 1978, Jubb et al. 1983) but seldom dropped by Liocarcinus puber. Nevertheless, the diet curve of $L$. puber feeding on mussels (Fig. 2) resembles that of $C$. maenas feeding on the same prey (Elner \& Hughes 1978). The fact that this appears to be due entirely to mechanical factors does not necessarily preclude optimal foraging by the former species, since the theory is not explicitly concerned with the mechanisms of prey selection. Rejection of suboptimal prey after brief manipulation provides a plausible and flexible mechanism which could lead to diet changes with prey density in C. maenas (Elner \& Hughes 1978). In $L$. puber, a variable rate of response to contacts with small suboptimal prey could have a similar effect, but only experiments involving a wide range of prey densities could evaluate the importance of all the potential causes of size-selective predation.

Some of the more recent versions of optimal foraging theory (Engen \& Stenseth 1984) lead to predictions which are different from those of previous versions (recently reviewed by Pyke 1984), but have not yet been used to analyse prey size-selection by crabs. Engen \& Stenseth (1984) extend the theory to consider the effects of simultaneous encounters with several prey, but not those of simultaneous search and handling. In the present study, even though prey densities were lower than those used in many other studies (Elner \& Hughes 1978, Hughes \& Seed 1981, Jubb et al. 1983), simultaneous contacts with prey were very frequent. In addition, crabs could search for and pick up a second prey while handling a first one, if the latter was not too large. In the field, simultaneous contacts and simultaneous search and handling could occur at high prey densities, for example in mussel beds.

Acknowledgements. This work was financed by a National Environment Research Council postgraduate studentship. I am grateful to Dr. R. N. Hughes for his advice and encouragement. The assistance provided by $\mathrm{Mr} \mathrm{G}$. P. Jones, who collected crabs for use in the experiments, is gratefully acknowledged. Dr. P. Lawton critically reviewed the manuscript.

\section{LITERATURE CITED}

ap Rheinallt, T. (1982). The foraging behaviour of some marine predators. Ph.D. thesis, Univ. of Wales, Bangor

ap Rheinallt, T., Hughes, R. N. (1985). Handling methods used by the velvet swimming crab Liocarcinus puber when feeding on molluscs and shore crabs. Mar. Ecol. Prog. Ser. 25: 63-70

Christiansen, M. E. (1969). Crustacea Decapoda Brachyura
(Marine invertebrates of Scandinavia No. 2). Universitetsforlaget, Oslo

Crothers, J. H. (1970). The distribution of crabs on rocky shores around the Dale Peninsula. Fld Std. 3: 263-274

Darnell, R. M. (1958). Food habits of fishes and larger invertebrates of Lake Pontchartrain, Louisiana, an estuarine community. Publs Inst. mar Sci. Univ. Tex. 5: 353-416

Elner, R. W., Hughes, R. N. (1978). Energy maximization in the diet of the shore crab, Carcinus maenas. J. Anim. Ecol. 47: 103-116

Engen, S., Stenseth, N. C. (1984). A general version of optimal foraging theory: the effect of simultaneous encounters. Theor. Pop. Biol. 26: 192-204

González Gurriarán, E. (1978). Introducción al estudio de la alimentación en la nécora, 'Macropipus puber' (L.) (Decapoda-Brachyura). Boln Inst. Esp. Oceanogr. 4 : 81-93

Hill, B. J. (1976). Natural food, foregut clearance-rate and activity of the crab Scylla serrata. Mar. Biol. 34: 109-116

Hill, B. J. (1979). Aspects of the feeding strategy of the predatory crab Scylla serrata. Mar. Biol. 55: 209-214

Hughes, R. N. (1979). Optimal diets under the energy maximization premise: the effects of recognition time and learning. Am. Nat. 113: 209-221

Hughes, R. N., Elner, R. W. (1979). Tactics of a predator, Carcinus maenas, and morphological responses of the prey, Nucella lapillus. J. Anim. Ecol. 48: 65-78

Hughes, R. N., Seed, R. (1981). Size selection of mussels by the blue crab Callinectes sapidus: energy maximizer or time minimizer? Mar. Ecol. Prog. Ser. 6: 83-89

Ingle, R. W. (1980). British crabs. British Museum (Natural History), Oxford Univ. Press

Jubb, C. A., Hughes, R. N., ap Rheinallt, T. (1983). Behavioural mechanisms of size-selection by crabs, Carcinus maenas (L.) feeding on mussels, Mytilus edulis L. J. exp. mar. Biol. Ecol. 66: 81-87

Klein Breteler, W. M. (1975). Food consumption, growth, and energy metabolism of juvenile shore crabs, Carcinus maenas. Neth. J. Sea Res. 9: 255-272

Lawton, P., Hughes, R. N. (1985). Foraging behaviour of the crab Cancer pagurus on the gastropods Nucella lapillus and Littorina littorea: comparisons with optimal foraging theory. Mar. Ecol. Prog. Ser. 27: 143-154

Neter, J., Wasserman, W. (1974). Applied linear statistical models. Richard D. Irwin, Homewood, Illinois

Paul, R. K. G. (1981). Natural diet, feeding and predatory activity of the crabs Callinectes arcuatus and C. toxotes (Decapoda, Brachyura, Portunidae). Mar. Ecol. Prog. Ser. 6: 91-99

Pyke, G. H. (1984). Optimal foraging theory: a critical review A. Rev. Ecol. Syst. 15: 523-575

Pyke, G. H., Pulliam, H. R., Charnov, E. L. (1977). Optimal foraging: a selective review of theory and tests. $Q$. Rev Biol. 52: 137-154

Ropes, J. W. (1968). The feeding habits of the green crab, Carcinus maenas (L.). Fish. Bull. Fish. Wildl. Serv. U.S. 67 183-203

Sokal, R. R., Rohlf, F. J. (1981). Biometry (2nd edition). W. H. Freeman, San Francisco

Tagatz, M. E. (1968). Biology of the blue crab, Callinectes sapidus Rathbun, in the St. Johns River, Florida. Fish. Bull. Fish. Wildl. Serv. U.S. $67:$ 17-33

Williams, M. J. (1982). Natural food and feeding in the commercial sand crab Portunus pelagicus Linnaeus, 1766 (Crustacea: Decapoda: Portunidae) in Moreton Bay, Queensland. J. exp. mar. Biol. Ecol. 59: 165-176 